\title{
ANALISIS EFISIENSI PEMASARAN TOMAT (Solanum Lycopersicum) DI KELURAHAN KALAMPANGAN KECAMATAN SABANGAU KOTA PALANGKA RAYA
}

\author{
${ }^{1}$ Edu Wiranto Purba, ${ }^{2}$ H. A. Zaki Yamani, ${ }^{3}$ Revi Sunaryati \\ ${ }^{1}$ Alumnus Program Studi Agribisnis Fakultas Pertanian Universitas Palangka Raya \\ ${ }^{2,3}$ Staf Pengajar Program Studi Agribisnis Fakultas Pertanian Universitas Palangka Raya \\ email:ahmad.zaki@agb.upr.co.id
}

\begin{abstract}
ABSTRAK
Tujuan dari penelitian ini adalah menganalisis saluran, lembaga pemasaran dan fungsi-fungsi pemasaran, menganalisis margin, biaya, keuntungan dan efisiensi pemasaran tomat di Kelurahan Kalampangan. Sistem pemasaran tomat di Kelurahan Kalampangan yaitu saluran pemasaran I dari petani ke konsumen dan saluran pemasaran II dari petani ke pedagang pengumpul ke konsumen. Fungsi-fungsi pemasaran yaitu pada saluran pemasaran I, fungsi fungsi penjualan, fungsi pengangkutan, fungsi penyimpanan, fungsi informasi pasar, penanggungan resiko sedangkan saluran pemasaran II, fungsi penjualan, fungsi pengangkutan, fungsi penyimpanan, fungsi informasi pasar, penanggungan resiko, standarisasi dan grading, fungsi pembiayaan. Pada saluran pemasaran I, margin, biaya, keuntungan, share petani dan efisiensi pemasaran tomat di kelurahan kalampangan yaitu margin pemasaran yang diperoleh Rp. 0 (nol), biaya pemasaran total sebesar Rp. 370.532, keuntungan pemasaran sebesar Rp. 3.029.468, farmer share sebesar 0 (nol) persen, dan efisiensi pemasaran sebesar 10,90 persen sedangkan pada saluran pemasaran II, margin, biaya, keuntungan, share petani dan efisiensi pemasaran tomat di kelurahan kalampangan yaitu margin pemasaran yang diperoleh Rp. 10.578.125, biaya pemasaran total sebesar Rp. 1.346.127, keuntungan pemasaran yaitu petani sebesar Rp. 6.346 .875 dan pedagang pengumpul sebesar Rp. 9.231.998, farmer share sebesar 0,375 persen, dan efisiensi pemasaran sebesar 9,39 persen.
\end{abstract}

Kata kunci : Tomat, Saluran Pemasaran, Margin Pemasaran, Biaya Pemasaran, Keuntungan Pemasaran, Share Petani, Efisiensi Pemasaran

\section{ABSTRACT}

The purpose of this research is to analyze channels, marketing institutions and marketing functions, analyze margins, costs, advantages and efficiency of tomato marketing in Kalampangan Village. Tomato marketing system in Kalampangan Village is marketing channel I from farmer to consumer and marketing channel II from farmer to collector to consumer. Marketing functions are in marketing channel I, sales function, transportation function, storage function, market information function, risk insurer while marketing channel II, sales function, transportation function, storage function, market information function, risk management, standardization and grading, financing function. In marketing channel I, margin, cost, profit, share of farmers and efficiency of tomato marketing in kalampangan village is marketing margin obtained rp. 0 (zero), total 
marketing costs of Rp. 370,532, marketing profits of Rp. 3,029,468, farmer share of 0 (zero) percent, and marketing efficiency of 10.90 percent while in marketing channels II, margin, cost, profit, share of farmers and tomato marketing efficiency in kalampangan village, namely marketing margin obtained Rp. 10,578,125 , total marketing costs amounted to Rp. 1,346,127, marketing profits were farmers amounted to Rp. 6,346,875 and collecting traders amounted to Rp. 9,231,998, farmer shares by 0.375 percent, and marketing efficiency of 9.39 percent.

Keywords : Tomatoes, Marketing Channels, Marketing Margins, Marketing Costs, Marketing Advantages, Farmer Share, Marketing Efficiency.

\section{PENDAHULUAN}

Sektor pertanian merupakan salah satu sektor yang menjadi penopang pertumbuhan perekonomian Indonesia. Sektor tersebut menjadi landasan bagi perkembangan pertanian di Indonesia untuk memajukan ekonomi masyarakat Indonesia untuk bertahan hidup dari masa sekarang dan masa depan. Khususnya pekembangan tanaman pangan, dan tanaman hortikultura yang berkontribusi besar terhadap pertanian di Indonesia. Pada Perkembangan luas panen, produksi dan produktivitas tomat di Kota Palangka Raya dari tahun 20162019 seperti pada tabel dibawah ini.

Tabel 1 Perkembangan Luas Panen, Produksi dan Produktivitas Tomat di Kota Palangka Raya Tahun 2016-2019.

\begin{tabular}{lcrrr}
\hline No. & Tahun & $\begin{array}{c}\text { Luas Panen } \\
(\mathrm{Ha})\end{array}$ & $\begin{array}{c}\text { Produksi } \\
\text { (Ton) }\end{array}$ & \multicolumn{1}{c}{$\begin{array}{c}\text { Produktivitas } \\
\text { (Ton/Ha) }\end{array}$} \\
\hline 1 & 2016 & 48 & 2.336 & 48.66 \\
2 & 2017 & 36 & 2.481 & 68.91 \\
3 & 2018 & 40 & 966 & 24.15 \\
4 & 2019 & 33 & 1.182 & 35.81 \\
\hline
\end{tabular}

Sumber: Badan Pusat Statistik Kota Palangka Raya, Tahun 2020.

Tabel 1. menunjukkan bahwa perkembangan produksi tomat di Kota Palangka Raya mengalami fluktuatif. Peningkatan produksi terbesar terjadi pada tahun 2017 sebesar 2.481 ton dengan luas panen sebesar 36 hektar dengan produktivitas sebesar 68.91 ton/ha sedangkan produksi terendah terjadi pada tahun 2018 sebesar 966 ton dengan luas panen sebesar 40 hektar dengan produktivitas sebesar 24.15 ton/ha. Dari hal ini dapat dilihat bahwa perkembangan produksi tomat di kota Palangka Raya mengalami fluktuatif dari tahun 2016 mengalami peningkatan hingga pada tahun 2017, kemudian menurun pada tahun 2018 dan mengalami peningkatan kembali pada tahun 2019, terjadinya fluktuatif ini disebabkan karena adanya peningkatan kualitas tanam tomat serta perawatan pada tanaman sehingga produksi mengalami fluktuatif setiap tahunnya dan mempengaruhi produktivitas. 
Tabel 2. Luas Panen, Produksi dan Produktivitas Tomat di Kota Palangka Raya berdasarkan Kecamatan, Tahun 2018

\begin{tabular}{|c|c|c|c|c|}
\hline \multirow[b]{2}{*}{ No. } & \multirow[b]{2}{*}{ Kecamatan } & \multicolumn{3}{|c|}{ Tomat } \\
\hline & & $\begin{array}{c}\text { Luas Panen } \\
(\mathrm{Ha})\end{array}$ & $\begin{array}{l}\text { Produksi } \\
\text { (Ton) }\end{array}$ & $\begin{array}{l}\text { Produktivitas } \\
\text { (Ton/Ha) }\end{array}$ \\
\hline 1 & Pahandut & 1 & 48 & 48 \\
\hline 2 & Sebangau & 10 & 204 & 20.4 \\
\hline 3 & Jekan Raya & 7 & 84 & 12 \\
\hline 4 & Bukit Batu & 9 & 714 & 79.33 \\
\hline 5 & Rakumpit & 4 & 132 & 33 \\
\hline Total & Palangka Raya & 33 & 1.182 & 35.81 \\
\hline
\end{tabular}

Sumber: Badan Pusat Statistik Kota Palangka Raya, Tahun 2020.

Tabel 2. menjelaskan bahwa setiap kecamatan memiliki luas lahan, produksi dan produktivitas yang berbeda di setiap kecamatan di Kota Palangka Raya yaitu pada tahun 2019 pada setiap kecamatannya, luas panen tertinggi tomat terdapat pada kecamatan Sebangau yaitu sebesar 10 Hektar, dengan produksi 204 ton dan produktivitas sebesar 20.4 ton/ha sedangkan luas lahan terendah pada kecamatan Pahandut dan Rakumpit yaitu sebesar 1 Hektar, dengan produksi 48 kuintal, dan produktivitas 48 ton/ha.

Dapat dilihat bahwa kecamatan sebangau memiliki produksi yang tinggi yaitu 204 ton, dari banyaknya produksi diperlukan adanya pemasaran. Dalam kegiatan pemasaran hasil produk pertanian dari produsen atau petani hingga ke konsumen dapat dilihat penyalurannya baik secara langsung maupun melewati lembaga-lembaga pemasaran. pemasaran petani ke konsumen memerlukan lembaga pemasaran, peran lembaga pemasaran tersebut unuk memudahkan petani tomat agar proses penjualan produksi tomat berjalan dengan cepat sampai kepada konsumen. Dengan adanya lembaga pemasaran tersebut juga dapat menyebabkan kenaikan pada biayabiaya pemasaran. biaya pemasaran tersebut kemudian diperhitungkan pada penentuan harga yang diberikan oleh pedagang kepada konsumen.

Kelurahan

Kalampangan

merupakan salah satu kelurahan yang ada di Kecamatan Sabangau. Dari data yang ada, Kalampangan merupakan daerah atau kawasan pertanian, yang dimana rata-rata pekerjaan masyarakyat di Kalampangan yaitu Petani. Dilihat dari petani penanam Tomat tersebut, adanya produksi tomat yang cukup banyak di daerah kalampangan sehingga menjadi peluang bagi para petani untuk melakukan usahatani Tanaman Tomat dan juga mempunyai peran bagi para Petani untuk mencukupi perekonomian para petani Tomat di Kelurahan Kalampangan.

Berdasarkan uraian diatas, penulis ingin mengetahui bagaimana Pemasaran Tomat yang dikelola dapat memberikan manfaat bagi para petani, lembaga-lembaga maupun pihak yang melakukan pemasaran terhadap buah Tomat. Serta ingin melihat tingkat efisiensi pemasaran Tomat yang ada di Kelurahan Kalampangan dan dapat melihat bagian yang diterima oleh Petani Tomat dalam Pemasaran Tomat di Kelurahan Kalampangan Kecamatan Sabangau Kota Palangka Raya. Maka penelitian ini bertujuan untuk 
Menganalisis Saluran, Lembaga Pemasaran dan Fungsi-fungsi pemasaran yang dilakukan dalam Pemasaran Tomat serta menganalisis Margin, Biaya, Keuntungan dan Efisiensi Pemasaran Tomat di Kelurahan Kalampangan Kecamatan Sabangau Kota Palangka Raya.

\section{METODE PENELITIAN}

\section{Lokasi dan Waktu Penelitian}

Penelitian ini dilaksanakan di Kelurahan Kalampangan Kecamatan Sabangau Kota Palangka Raya. Penentuan lokasi penelitian ini dilakukan secara sengaja (purposive). dengan pertimbangan bahwa di Kelurahan Kalampangan Kecamatan Sabangau Kota Palangka Raya terdapat Petani Tomat yang masih aktif dan Pedagang yang melakukan pemasaran Tomat. Penelitian ini dilaksanakan selama 3 (tiga) Bulan, yaitu dari Bulan September sampai Bulan November 2020

\section{Metode Penelitian Survey}

Adapun pengambilan sampel pada penelitian ini menggunakan metode non-probability sampling dengan jenis pengambilan yaitu menggunakan Purposive sampling (sengaja), Dari data informasi dari penyuluh pertanian lapangan kalampangan yang diperoleh diketahui jumlah petani yang sedang memanen tomat di kelurahan kalampangan ada sebanyak 8 (delapan) orang petani, sehingga jumlah responden yang mewakili petani tomat berjumlah 8 (delapan) orang petani. Dan pengambilan sampel pedagang menggunakan Snowball Sampling, Dari data informasi yang di dapat di lapangan sebanyak 8 (delapan) orang pedagang pengumpul yang mewakili sampel pedagang.

\section{Metode Pengumpulan Data}

Data yang dikumpulkan meliputi data primer dan data sekunder. Data primer merupakan data yang diperoleh dari pengamatan dan wawancara langsung dengan responden menggunakan daftar pertanyaan (kuisioner). Pengambilan data primer dilakukan melalui wawancara dan pengamatan langsung dengan petani tanaman tomat dan pedagang berdasarkan isi pertanyaan pada kuisioner dan data sekunder merupakan data yang diperoleh dari instansi atau lembaga terkait guna menunjang penelitian.

\section{Metode Pengolahan dan Analisis Data}

Metode analisis yang digunakan dalam penelitian ini meliputi analisis deskriptif dan analisis kuantitatif.

1. Untuk menjawab tujuan penelitian yang pertama yaitu untuk menganalisis Saluran, Lembaga Pemasaran dan Fungsi-fungsi pemasaran dianalisis menggunakan analisis deskriptif yang merupakan dengan menguraikan hasil yang didapat dari pengamatan di lapangan dalam bentuk kalimat, sehingga memberikan gambaran yang jelas mengenai saluran pemasaran tomat yang dilakukan oleh lembaga pemasaran yang terlibat dan fungsifungsi pemasaran.

2. Untuk menjawab tujuan penelitian kedua yaitu untuk menganalisis Margin, Biaya, Keuntungan dan Efisiensi Pemasaran Tomat digunakan rumus;

Besarnya margin pemasaran dihitung dengan menggunakan rumus persamaan: 
Keterangan:

$$
\mathrm{Mj}=\mathrm{Hk}-\mathrm{Hp}
$$

$\mathrm{Mj}=$ Margin Pemasaran Tomat $\mathrm{di}$ Kelurahan Kalampangan

$\mathrm{Hk}=$ Harga Tomat ditingkat Konsumen di Kelurahan Kalampangan

$\mathrm{Hp}=$ Harga Tomat ditingkat Produsen di Kelurahan Kalampangan

Biaya pemasaran

Biaya pemasaran merupakan biaya yang dikeluarkan untuk keperluan pemasaran, meliputi biaya pengangkutan, biaya pengemasan, dan biaya retribusi. Biaya pemasaran dapat dihitung dengan persamaan berikut:

$$
\mathrm{BPi}=\mathrm{MPi}-\mathrm{Ui}
$$

Keterangan :

$\mathrm{BP}=$ Biaya Pemasaran Lembaga

tingkat ke-i (Rp)

$\mathrm{MP}=$ Margin Pemasaran Lembaga

tingkat ke-i (Rp)

$\mathrm{U}=$ Keuntungan lembaga tingkat ke-i (Rp)

Besarnya Keuntungan lembaga pemasaran dapat dihitung dengan persamaan berikut:

$$
\text { MPi - BPi }
$$

$$
\mathrm{Ui}=
$$

Keterangan :

$\mathrm{BP}=$ Biaya Pemasaran Lembaga

tingkat ke-i (Rp)

MP = Margin Pemasaran Lembaga

tingkat ke-i (Rp)

Tabel 3 Umur Petani Sampel di Kelurahan Kalampangan Kecamatan Sabangau Kota Palangka Raya, 2020.

\begin{tabular}{ccc}
\hline No. & Umur (Tahun) & Jumlah Petani (KK) \\
\hline 1. & $0-14$ & - \\
2. & $15-20$ & - \\
3. & $21-25$ & - \\
4. & $26-30$ & 3 \\
5. & $31-35$ & - \\
6. & $36-40$ & 1 \\
7. & $41-45$ & 1 \\
8. & $46-50$ & - \\
9. & $51-55$ & 1 \\
10. & $56-60$ & 29
\end{tabular}
(Rp)

Untuk menganalisis besarnya efisiensi pemasaran dapat dihitung dengan menggunakan persamaan:

$$
\frac{\mathrm{Tb}}{\mathrm{TNP}} \times 100 \%
$$

$$
\mathrm{EP}=
$$

Keterangan :

$\mathrm{EP}=$ Efisiensi Pemasaran (\%)

$\mathrm{Tb}=$ Total Biaya (Rp)

Tnp $=$ Total Nilai Produk $(\mathrm{Rp})$

Untuk mengetahui Farmer's share atau bagian yang diterima petani:

$$
\mathrm{FS}=\underline{\mathrm{Pf}} \mathrm{x}
$$

Keterangan:

Fs = Farmer's share (Bagian yang di terima Petani Tomat (\%)

Pf = Price farmer (Harga jual ditingkat Produsen Tomat) (Rp/kg)

$\mathrm{Pr} \quad=$ Price retail (Harga di tingkat Lembaga Pemasaran Tomat (Rp/kg)

\section{HASIL DAN PEMBAHASAN}

\section{Keadaan Umum Petani Sampel}

$\mathrm{U}=$ Keuntungan lembaga tingkat ke-i 
11. $61-65$ $\frac{2}{8}$

Sumber: Data Primer yang diolah, Tahun 2020.

Petani sampel yang terambil dimulai dari umur 31 tahun sampai dengan petani lebih dari umur 65 tahun.

Tabel 4 Tingkat Pendidikan Formal Petani Sampel di Kelurahan Kalampangan Kecamatan Sabangau Kota Palangka Raya, 2020.

\begin{tabular}{clr}
\hline No. & \multicolumn{1}{c}{ Jenjang Pendidikan } & Jumlah Petani (Orang) \\
\hline 1. & Tidak Lulus SD & - \\
2. & Lulus SD & 6 \\
3. & Lulus SMP & - \\
4. & Lulus SMA & 2 \\
5. & Perguruan Tinggi & - \\
\hline & \multicolumn{2}{c}{ Total }
\end{tabular}

Sumber: Data Primer yang diolah, Tahun 2020.

Tingkat pendidikan formal petani lulusan SD yaitu sebanyak 6 orang, dan sampel di kelurahan kalampangan yaitu lulusan SMA sebanyak 2 orang.

Tabel 5 Jumlah Tanggungan Petani Sampel di Kelurahan Kalampangan Kecamatan Sabangau Kota Palangka Raya, 2020.

\begin{tabular}{ccr}
\hline No. & Jumlah Tanggungan & Jumlah Petani (Orang) \\
\hline 1. & $1-2$ & 4 \\
2. & $3-4$ & 4 \\
3. & $5-6$ & - \\
\hline & Total & 8 \\
\hline
\end{tabular}

Sumber: Data Primer yang diolah, Tahun 2020.

Jumlah tanggungan petani orang, dan jumlah tanggungan 3-4 sampel di kelurahan kalampangan yaitu jumlah tanggungan 1-2 sebanyak 4 sebanyak 4 orang.

\section{Keadaan Umum Pedagang}

Tabel 6 Umur Pedagang Sampel di Kelurahan Kalampangan Kecamatan Sabangau Kota Palangka Raya, 2020.

\begin{tabular}{ccc}
\hline No. & Umur (Tahun) & Jumlah Pedagang $(\mathrm{KK})$ \\
\hline 1. & $0-14$ & - \\
2. & $15-20$ & 1 \\
3. & $21-25$ & - \\
4. & $26-30$ & 1 \\
5. & $31-35$ & 2 \\
6. & $36-40$ & 2 \\
7. & $41-45$ & 2 \\
8. & $46-50$ & - \\
9. & $51-55$ & - \\
10. & $56-60$ &
\end{tabular}


11. 61-65

Total

Sumber: Data Primer yang diolah, Tahun 2020.

Pedagang sampel yang banyak menjual tomat ialah pedagang yang berumur 3640 tahun, 41-45 tahun dan umur 46-50.
Pedagang sampel yang terambil dimulai dari umur 21 tahun sampai dengan pedagang umur 50 tahun.

Tabel 7 Tingkat Pendidikan Formal Pedagang Sampel di Kelurahan Kalampangan Kecamatan Sabangau Kota Palangka Raya, 2020.

\begin{tabular}{ccc}
\hline No. & Jenjang Pendidikan & $\begin{array}{c}\text { Jumlah Pedagang } \\
\text { (Orang) }\end{array}$ \\
\hline 1. & Tidak Lulus SD & - \\
2. & Lulus SD & 1 \\
3. & Lulus SMP & 3 \\
4. & Lulus SMA & 4 \\
5. & Perguruan Tinggi & - \\
\hline & Total & 8 \\
\hline
\end{tabular}

Sumber: Data Primer yang diolah, Tahun 2020.

Tingkat pendidikan formal sebanyak 3 orang dan lulusan SMA pedagang sampel yaitu lulusan SD yaitu sebanyak 4 orang. sebanyak 1 orang, lulusan SMP yaitu Tabel 8 Jumlah Tanggungan Petani Sampel di kelurahan Kalampangan Kecamatan Sabangau Kota Palangka Raya, 2020.

\begin{tabular}{ccc}
\hline No. & Jumlah Tanggungan & Jumlah Pedagang (Orang) \\
\hline 1. & $1-2$ & 6 \\
2. & $3-4$ & 2 \\
3. & $5-6$ & - \\
\hline & Total & 8 \\
\hline
\end{tabular}

Sumber: Data Primer yang diolah, Tahun 2020.

Jumlah tanggungan pdagang sampel yaitu jumlah tanggungan 1-2 sebanyak 6 orang, dan jumlah tanggungan 3-4 sebanyak 2 orang.

\section{Saluran dan Lembaga Pemasaran}

Berdasarkan hasil pengamatan selama melakukan penelitian di Kelurahan Kalampangan Kecamatan Sabangau Kota Palangka Raya terdapat dua macam saluran pemasaran tomat, saluran pemasaran I, petani langsung menjual kepada konsumen sedangkan saluran pemasaran II melibatkan lembaga pemasaran sampai kepada konsumen.

Pada saluran pemasaran I hanya melibatkan petani dan konsumen. Petani melakukan penjualan tomat hasil panennya sendiri ke pasar besar pada saluran pemasaran II terdapat 1 lembaga pemasaran yang terlibat yaitu pedagang pengumpul. petani melakukan penjulan kepada pedagang pengumpul dan pedagang pengumpul menjual kepada konsumen. Pada saluran pemasaran II, terdapat 8 orang petani yang melakukan 
penjualan tomat ke pedagang pengumpul.

\section{Fungsi Pertukaran}

Pada saluran pemasaran I, petani tidak melakukan fungsi pembelian dan melakukan fungsi penjualan kepada konsumen. terdapat 1 (satu) orang petani yang melakukan penjualan tomat ke pasar besar dan pada saluran pemasaran II, petani tidak melakukan fungsi pembelian tomat dan melakukan fungsi penjualan.

\section{Fungsi Fisik}

Pada saluran pemasaran I, petani dalam memasarkan tomat melakukan fungsi pengangkutan dengan alat transportasi berupa mobil pick up dan pada saluran pemasaran II, petani tidak melakukan fungsi pengangkutan, Pedagang pengumpul dalam memasarkan tomat melakukan fungsi pengangkutan dengan alat transportasi berupa mobil pick up.

\section{Fungsi Fasilitas}

Pada saluran pemasaran I, petani dalam mendapatkan informasi pasar melalui pedagang pengumpul, cara penanggungan resiko terhadap pemasaran tomat yaitu petani melakukan pemanenan buah tomat yang berwarna kuning, tidak melakukan standarisasi, melakukan fungsi pembiayaan sedangakan Pada saluran pemasaran II, petani dalam mendapatkan informasi pasar melalui pedagang pengumpul dan Pedagang pengumpul dalam mendapatkan informasi pasar melalui pedagang pengumpul yang ada di pasar besar dan mengikuti informasi pasar dari pedagang luar daerah, cara penanggungan resiko petani terhadap pemasaran tomat yaitu petani melakukan pemanenan buah tomat yang berwarna kuning dan cara penanggungan resiko petani pedagang pengumpul melakukan pembelian tomat berwarna kuning, petani dan pedagang pengumpul tidak melakukan standarisasi dan granding, Petani melakukan fungsi pembiayaan dengan modal usaha sendiri dan Pedagang pengumpul melakukan fungsi pembiayaan dimodalkan terlebih dahulu oleh petani.

\section{Margin Pemasaran}

Margin pemasaran pada saluran I yaitu margin pemasaran tomat masih 0 persen sedangkan margin pada saluran pemasaran II yaitu margin pemasaran tomat sebesar Rp. 10.578.125.

\section{Biaya Pemasaran}

Biaya pemasaran pada saluran pemasaran I yaitu yang ditanggung oleh 1 (satu) orang petani menjual tomat langsung ke konsumen yaitu biaya plastik sebesar Rp.105.000, biaya transportasi sebesar Rp.250.000, biaya retribusi sebesar Rp.15.000, biaya timbangan sebesar Rp.532 dan jumlah biaya pemasaran sebesar Rp.370.532 sedangkan biaya pemasaran pada saluran pemasaran II yaitu petani tidak memiliki biaya pemasaran dan pedagang pengumpul biaya pemasaran antara lain yaitu biaya plastik sebesar Rp.436.875, biaya transportasi sebesar Rp.856.250, biaya retribusi sebesar Rp.51.375, biaya timbangan sebesar Rp.1.627 dan jumlah biaya pemasaran sebesar Rp.1.346.5127.

\section{Keuntungan Pemasaran}

Keuntungan pemasaran pada saluran pemasaran I yaitu petani mendapatkan total pendapatan sebesar Rp. 3.400.000 dengan biaya sebesar Rp. 370.532 dengan keuntungan total sebesar Rp. 3.029.468. sedangkan pada saluran pemasaran II yaitu petani mendapatkan total pendapatan sebesar Rp. 6.346.875 sedangkan pedagang pengumpul mendapatkan total pendapatan sebesar Rp. 16.925.000 
dengan biaya sebesar Rp 1.346.127 dengan keuntungan total sebesar Rp. 9.231.998.

\section{Farmer Share}

Farmer share pada saluran pemasaran I yaitu petani dalam saluran pemasaran ini masih mendapatkan bagian yang diterima masih $0 \%$ sedangkan Farmer share yang didapat pada saluran pemasaran II yaitu dari ratarata 8 (delapan) petani dan pedagang pengumpul didapat bagian yang diterima petani sebesar $0,375 \%$.

\section{Analisis Efisiensi Pemasaran}

Efisiensi Pemasaran pada saluran pemasaran I yaitu sebesar $10,90 \%$, hal ini didapat dari penerimaan total petani tomat dibagi dengan biaya pemasaran dikali $100 \%$. Faktor yang mempengaruhi efisiensi terdapat dari jumlah tomat yang dipasarkan dengan harga tomat dan biaya pemasaran tomat sedangkan Efisiensi Pemasaran yang didapat pada saluran pemasaran II yaitu dari rata-rata 8 (delapan) petani dan pedagang pengumpul didapat efisiensi pemasaran tomat sebesar 9,39\%. Nilai efisiensi pemasaran dapat diukur apabila, semakin kecil persentase efisiensi pemasaran yang diperoleh maka semakin tinggi nilai efisiensi pemasaran tersebut dan dikatakan efisien. Jadi pada saluran pemasaran II lebih efisien dibandingkan saluran pemasaran I, dikarenakan pada saluran pemasaran I, efisiensi sebesar 10,90\% sedangkan efisiensi pada saluran pemasaran II sebesar 9,39\%. Faktor yang mempengaruhi efisiensi terdapat dari jumlah tomat yang dipasarkan dengan harga tomat dan biaya pemasaran tomat.

\section{KESIMPULAN DAN SARAN}

\section{Kesimpulan}

\begin{tabular}{lrr}
\multicolumn{2}{c}{ Berdasarkan hasil } & penelitian \\
dilapangan & mengenai & kegiatan \\
pemasaran & tomat di & Kelurahan
\end{tabular} Kalampangan Kecamatan Sabangau Kota Palangka Raya, maka dapat disimpulkan sebagai berikut:

1. Sistem pemasaran tomat di Kelurahan Kalampangan terdapat dua saluran pemasaran yaitu saluran pemasaran I dari petani ke konsumen sedangkan saluran pemasaran II dari petani ke pedagang pengumpul sampai kepada konsumen.serta lembaga yang berperan dalam pemasaran tomar yaitu pedagang pengumpul. Fungsifungsi pemasaran yang dilakukan selama pemasaran yaitu pada saluran pemasaran I, fungsi-fungsi pemasaran yang dilakukan adalah fungsi pertukaran berupa (fungsi penjualan), fungsi fisik berupa (fungsi pengangkutan, fungsi penyimpanan), fungsi fasilitas berupa (informasi pasar, penanggungan resiko) sedangkan saluran pemasaran II, fungsi-fungsi pemasaran yang dilakukan adalah fungsi pertukaran berupa (fungsi pembelian dan penjualan), fungsi fisik berupa (fungsi pengangkutan, fungsi penyimpanan), fungsi fasilitas berupa (informasi pasar, penanggungan resiko, fungsi pembiayaan).

2. Pada saluran pemasaran I, margin, biaya, keuntungan, share petani dan efisiensi pemasaran tomat di kelurahan kalampangan yaitu margin pemasaran yang diperoleh Rp. 0 (nol), biaya pemasaran total sebesar $\mathrm{Rp}$. 370.532, keuntungan pemasaran sebesar Rp. 3.029.468, farmer share sebesar 0 (nol) persen, dan efisiensi pemasaran sebesar 10,90 persen sedangkan pada saluran pemasaran II, margin, biaya, keuntungan, share petani dan efisiensi pemasaran tomat 
di kelurahan kalampangan yaitu margin pemasaran yang diperoleh $\mathrm{Rp}$. 10.578.125, biaya pemasaran total sebesar Rp. 1.346.127, keuntungan pemasaran yaitu petani sebesar Rp. 6.346.875 dan pedagang pengumpul sebesar Rp. 9.231.998, farmer share sebesar 0,375 persen, dan efisiensi pemasaran sebesar 9,39 persen. Nilai efisiensi pemasaran dapat diukur apabila, semakin kecil persentase efisiensi pemasaran yang diperoleh maka semakin tinggi nilai efisiensi pemasaran tersebut dan dikatakan efisien. Semakin tinggi persentase efisiensi pemasaran yang diperoleh maka semakin rendah nilai efisiensi pemasaran tersebut dan dikatakan tidak efisien. Jadi pada saluran pemasaran II lebih efisien dibandingkan saluran pemasaran I, dikarenakan pada saluran pemasaran I, efisiensi sebesar 10,90 persen sedangkan efisiensi pada saluran pemasaran II sebesar 9,39 Persen. Faktor yang mempengaruhi efisiensi terdapat dari jumlah tomat yang dipasarkan dengan harga tomat dan biaya pemasaran tomat.

\section{Saran}

1. Petani dapat memilih atau menerapkan saluran pemasaran II untuk diterapkan untuk pemasaran tomat dikarenakan lebih efisien terhadap biaya-biaya pemasaran dan juga memperoleh keuntungan yang cukup serta mempunyai lembaga yang meneruskan buah tomat ke konsumen.

2. Pemerintah di Kelurahan Kalampangan diharapkan untuk dapat mendampingi para petani dan pedagang untuk menghidupkan lembaga kelurahan atau koperasi ditingkat kelurahan agar petani dengan mudah untuk memasarkan hasil pertaniannya dengan hargaharga yang stabil untuk para petani dan pedagang.

\section{DAFTAR PUSTAKA}

Anwar, K. 2016. Meraup Untung Melimpah dengan Berkebun Tomat. Sukma Jaya Depok. Vilam Media

Badan Pusat Statistik. Kota Palangka Raya. 2020. Kota Palangka Raya Dalam Angka 2020.

Bintang, P., Pujiharto dan Watemin. 2016. Analisis Pemasaran Jagung (Zae Mays L) di Desa Karangmalang Kecamatan Kedung Banteng Kabupaten Tegal. Jurnal AGRITECH 18 (2): 14111063

Fatimah, N. 2011. Analisis Pemasaran Kentang (Solanum tubeserum L) di Kabupaten Wonosobo. Fakultas Pertanian, Universitas Sebelas Maret, Surakarta.

Hartono, H., Hutomo, K dan Mayangsari, M. 2012. Pengaruh Strategi Pemasaran Terhadap Peningkatan Penjualan Pada Perusahaan Dengan Menetapkan Alumni Dan Mahasiswa Universitas Bina Nusantara Sebagai Objek Penelitian. Binus Business Review 3 (2) : 882-897

Suhanak dan Sujana, N. 2014. Analisis Biaya Pemasaran Sebagai Salah Satu Alat Untuk Pengendalian Biaya Komersial. Jurnal Administrasi Bisnis 13 (1)

Istiyanti, E. 2010. Efisiensi Pemasaran Cabai Merah Keriting Di 
Kecamatan Ngemplak

Kabupaten Sleman. Jurnal

Pertanian MAPETA 7 (2): 72-144

Iwan, I. 2016. Analisis Marjin

Pemasaran, Efisiensi

Pemasaran dan Keuntungan pada Tataniaga Cengkeh Kabupaten Seram Bagian Barat, Provinsi Maluku (Studi Kasus Di Desa Luhu). Jurnal Riset Edisi III 2 (002)

Kohl, Rl dan Uhl JN. 1985. Marketing of Agricultural Products. USA : Mc. Milan Inc

Kotler. 2002. Manajemen Pemasaran : Analisis Pemasaran, Implementasi dan Pengendalian. Salemba Empat. Jakarta. 2000. Manajemen Pemasaran : Analisis, Pemasaran control 1. Jilid 1. Penerbit PT. Prenhallindo. Jakarta.

Pracaya. 1998. Bertanam Tomat. Kanisius. Yogyakarta.

Rahmanta. 2016. Analisis Pemasarn Jagung di Kabupaten Labuhan Batu Selatan. QE journal 5 (4)

Sari, N. 2017. Efisiensi Pemasaran Jagung Di Kelurahan Kalampangan Kecamatan Sabangau Kota Palangka Raya. Fakultas Pertanian. Universitas Palangka Raya.
Shinta, A. 2011. Manajemen Pemasaran.

Elektronik Pertama dan

Terbesar di Indonesia. Malang.

Soekartawati. 1993. Prinsip Dasar Ekonomi Pertanian. Raja Grafindo Persada. Jakarta. 2002. Prinsip Dasar Manajemen Pemasaran Hasil-Hasil Pertanian Teori dan Aplikasinya. Ed L, Cet.3. PT Raja Grafindo Persada. Jakarta

Swastha, B. 1997. Manajemen Pemasaran Modern. Liberty, Yogyakarta

Tim Penulis Penebar Swadaya, 2009. Budidaya Tomat Secara Komersil. Depok. Penebar Swadaya. Jakarta.

Wulandari. 2008. Analisis Pemasaran Tahu Di Kecamatan Kartasutra Kabupaten Sukoharjo. Skripsi SP. Fakultas Pertanian. Universitas Sebelas Maret. Surakarta

Zuraida dan Wayaningsih, Yayu Minta. 2015. Efisiensi Pemasaran Kacang Tanah (Arachis hypogeae L) di Kelurahan Landasan Ulin Tengah Kecamatan Landasan Ulin Kota Banjarbaru Provinsi Kalimantan Selatan. Jurnal Ziraa'ah 40 (3): 2355-3 